\title{
Targeted leptin receptor blockade: role of ventral tegmental area and nucleus of the solitary tract leptin receptors in body weight homeostasis
}

\author{
M Matheny ${ }^{1}$, K Y E Strehler ${ }^{1}$, M King $^{1,2}$, N Tümer $^{1,2}$ and P J Scarpace ${ }^{1}$ \\ 1Department of Pharmacology and Therapeutics, College of Medicine, University of Florida, PO Box 100267, \\ Gainesville, Florida 32610, USA \\ ${ }^{2}$ Department of Veterans Affairs, Medical Center, Gainesville, Florida 32608-1197, USA
}

Correspondence should be addressed to P J Scarpace Email scarpace@ufl.edu

\begin{abstract}
The present investigation examined whether leptin stimulation of ventral tegmental area (VTA) or nucleus of the solitary tract (NTS) has a role in body weight homeostasis independent of the medial basal hypothalamus (MBH). To this end, recombinant adenoassociated viral techniques were employed to target leptin overexpression or overexpression of a dominant negative leptin mutant (leptin antagonist). Leptin antagonist overexpression in MBH or VTA increased food intake and body weight to similar extents over 14 days in rats. Simultaneous overexpression of leptin in VTA with antagonist in MBH resulted in food intake and body weight gain that were less than with control treatment but greater than with leptin alone in VTA. Notably, leptin overexpression in VTA increased P-STAT3 in MBH along with VTA, and leptin antagonist overexpression in the VTA partially attenuated P-STAT3 levels in $\mathrm{MBH}$. Interestingly, leptin antagonist overexpression elevated body weight gain, but leptin overexpression in the NTS failed to modulate either food intake or body weight despite increased P-STAT3. These data suggest that leptin function in the VTA participates in the chronic regulation of food consumption and body weight in response to stimulation or blockade of VTA leptin receptors. Moreover, one component of VTA-leptin action appears to be independent of the $\mathrm{MBH}$, and another component appears to be related to leptin receptor-mediated P-STAT3 activation in the MBH. Finally, leptin receptors in the NTS are necessary for normal energy homeostasis, but mostly they appear to have a permissive role. Direct leptin activation of NTS slightly increases UCP1 levels, but has little effect on food consumption or body weight.
\end{abstract}
Key Words
- leptin
- gene therapy
signal transduction
- neuroendocrinology

\section{Introduction}

The adipocyte-derived hormone, leptin, regulates appetite and energy expenditure through its action in the hypothalamus and other brain sites (Li 2011). Our previous studies involving central leptin gene delivery (leptin overexpression) into the third ventricle produced leptin elevation in the cerebral spinal fluid (Scarpace http://joe.endocrinology-journals.org DOI: 10.1530/JOE-13-0455
(C) 2014 Society for Endocrinology Printed in Great Britain
Journal of Endocrinology

(2014) 222, 27-41 
et al. 2002) and stimulation of leptin signaling in several brain regions (Matheny et al. 2011). Therefore, the observed physiological effects of leptin overexpression impinge upon a distributed neural network that includes an integration of leptin activity in many, if not all brain regions bearing functional leptin receptors. It is currently unclear if leptin function in an individual brain region is dissociable from that of other regions.

The arcuate nucleus (ARC) of the hypothalamus within the forebrain (Scarpace et al. 2012), the ventral tegmental area (VTA) within the midbrain (Bruijnzeel et al. 2011), and the nucleus of the solitary track (NTS) within the hindbrain (Grill \& Hayes 2012) are three regions responsive to direct leptin stimulation. Although leptin action in the hypothalamic region is firmly established, physiological regulation of body weight by leptin in the VTA midbrain and NTS hindbrain is still under investigation. Although leptin receptors in these regions couple to predictable signaling pathways (Grill \& Hayes 2012, Scarpace et al. 2012), the role in long-term body weight homeostasis is unclear. Knockdown of leptin receptors in the midbrain demonstrated a role for leptin in reward-based feeding without discernible effect on body weight (Davis et al. 2011). By contrast, direct leptin injection into the VTA induces short-term decreases in food consumption and body weight (Bruijnzeel et al. 2011) and our previous report demonstrating that chronic leptin overexpression in the VTA ameliorates body weight gain and tempers food consumption to the same extent as leptin overexpression in the medial basal hypothalamus (MBH) supports a role for leptin VTA action in long-term body weight homeostasis (Scarpace et al. 2012). In the latter study, these physiological responses to targeted leptin overexpression in the VTA or MBH were accompanied by elevated phosphorylation of STAT3 (P-STAT3) within the respective brain sites. Moreover, VTA leptin overexpression also stimulated P-STAT3 in the $\mathrm{MBH}$, whereas leptin overexpression in the $\mathrm{MBH}$ did not evoke activation of P-STAT3 in the VTA. This unidirectional trans-stimulation was apparently not due to migration of either the vector or the gene product, suggesting that the activation of hypothalamic P-STAT3 was not simply inadvertent (Scarpace et al. 2012). However, it remains uncertain whether leptin activation of the VTA on body weight regulation is independent, co-dependent on the $\mathrm{MBH}$, or has no role, and therefore, the observed body weight reductions are solely the result of inadvertent action of leptin in the $\mathrm{MBH}$.

Leptin receptors in the NTS are required for the maintenance of body weight. Knockdown or ablation of leptin receptors in the NTS results in increased body weight gain (Hayes et al. 2010, Scott et al. 2011). Whether activation of leptin receptors by exogenous leptin has a direct effect on food intake or body weight is less certain. Central leptin infusion into the fourth cerebral ventricle, in the vicinity of the NTS, activates NTS leptin receptor signaling and is associated with diminished body weight and food consumption (Grill \& Hayes 2012). However, these studies cannot rule out the inadvertent activation of hypothalamic leptin receptors due to the central infusion. For example, both fourth ventricle and lateral ventricle leptin infusions induce physiological responses and activate hypothalamic leptin signaling to similar degrees (Ruiter et al. 2010). The responses to fourth ventricle leptin infusion may be the inadvertent activation of hypothalamic leptin receptors, and thus, it is unclear if direct leptin stimulation of the NTS participates in body weight regulation.

The purpose of the present investigation was to determine whether direct leptin stimulation of the VTA or NTS has a role in long-term body weight homeostasis independent of the $\mathrm{MBH}$. To this end, recombinant adeno-associated viral techniques were employed to target leptin overexpression in the VTA or NTS coupled with the simultaneous overexpression of a dominant negative leptin mutant (leptin antagonist) in the MBH. Food intake and body weight (BW) were examined over $2-3$ weeks and leptin signaling was evaluated at death in F344 x Brown Norway (F344xBN) male rats.

\section{Materials and methods}

\section{Experimental animals}

Three-month-old male F344xBN rats were obtained from Harlan Sprague-Dawley (Indianapolis, IN, USA). Upon arrival, rats were examined and remained in quarantine for 1 week. Animal care procedures were in accordance with the principles of the Guide to the Care and Use of Experimental Animals, and the protocols were approved by the University of Florida Institutional Animal Care and Use Committee. Rats were housed individually with a $12 \mathrm{~h}$ light:12 h darkness cycle (0700 to $1900 \mathrm{~h}$ ) and were fed on a standard rodent chow $(17 \% \mathrm{kcal}$ from fat, no sucrose, $3.3 \mathrm{kcal} / \mathrm{g}$, diet 7912, Harlan Teklad; Madison, WI, USA).

\section{Experimental design}

This study consists of four experiments. In Experiment 1, recombinant adeno-associated virus (rAAV) encoding either green fluorescent protein (rAAV-control) or a

Published by Bioscientifica Ltd 
modified version of the rat leptin gene that acts as a dominant negative antagonist (rAAV-leptin Antg) was administered in rats by microinjection into the $\mathrm{MBH}$ or VTA for 14 days (controls, $n=13$; rAAV-Antg MBH, $n=7$; and rAAV-Antg VTA, $n=8$ ). One-half of the control rats received the GFP vector into the MBH $(n=7)$ and the other half received the green fluorescent protein (GFP) vector into the VTA $(n=6)$. Rats were allowed to access food and water ad libitum, and food consumption and body weight were recorded daily. Fresh food was provided weekly. Food consumption was determined by difference in the weight of remaining food accounting for spillage. Physiological responses were not different between sub-controls and these rats were subsequently treated as one control group $(n=13)$. Before death, at day 14, those rats treated with control vector were divided into two groups and administered by i.c.v. injection either artificial cerebral spinal fluid (ACSF, $n=6$ ) or leptin (40 ng, $n=7$ ), whereas those treated with rAAVleptin antagonist were administered leptin (40 ng) to determine leptin signaling in MBH and VTA brain regions.

In Experiment 2, three groups of rats were given two injections of rAAV vectors ( $n=7-8 /$ group): in the first group, the rAAV-GFP vector was delivered into VTA and into $\mathrm{MBH}$ (rAAV-control); in the second group, a rAAV vector encoding rat leptin (rAAV-leptin) was delivered to the VTA and rAAV-GFP to the MBH (rAAV-leptin VTA); and in the third group, rAAV-leptin was delivered to the VTA and rAAV-leptin antagonist to the MBH (rAAV-leptin VTA/Antg MBH).

In Experiment 3, three groups of rats were given two injections of rAAV vectors ( $n=7 /$ group): in the first group, the rAAV-GFP vector was delivered into NTS and into MBH (rAAV-control); in the second group, rAAV-leptin was delivered to the NTS and rAAV-GFP to the MBH (rAAVleptin NTS); and in the third group, rAAV-leptin was delivered to the NTS and rAAV-leptin antagonist to the MBH (leptin NTS/Antg MBH).

In Experiment 4 , three groups of rats ( $n=8 /$ group) were given a single injection of a rAAV-vector to the NTS, either rAAV-GFP, rAAV-leptin, or rAAV-leptin antagonist.

\section{Production of rAAV vectors}

Rat leptin antagonist DNA was a modification of a previously described construct (Matheny et al. 2009). WT sequence, TTGGACCTT, corresponding to amino acids leucine (L39), aspartic acid (D40), and phenylalanine (F41), was mutated to GCAGCCGCC, corresponding to alanine, alanine, and alanine. In this study, this construct was further modified by mutating GAC, corresponding to aspartic acid (D23), to CTG, corresponding to leucine. The sequence of the leptin antagonist construct was verified after PCR-based mutagenesis.

Viral vectors (serotype $1 \mathrm{rAAV}$ ) encoding rat leptin or leptin antagonist cDNA were under the control of a chicken $\beta$-actin promoter and were packaged by the University of Florida vector core or Vectorbiolabs (Philadelphia, PA, USA).

\section{Administration of rAAV-vector}

In Experiment 1 , a single dose $\left(5 \times 10^{12}\right.$ viral genomes $\left./ \mathrm{ml}\right)$ of rAAV-GFP $(1 \mu \mathrm{l})$ was unilaterally delivered by microinjection; in half of the control animals, the injections were directed into the $\mathrm{MBH}$, right of midline, targeting the ARC, and in the other half, the injections targeted the VTA. In parallel, the experimental animals received an equivalent dose of rAAV-leptin antagonist delivered by microinjection into the $\mathrm{MBH}$, right of midline, or into the VTA. In experiments 2 and 3, each rat was injected at two sites, as described in the experimental design section. The coordinates for the injection targeting the $\mathrm{MBH}$, right of midline, were $2 \mathrm{~mm}$ posterior to Bregma, $0.4 \mathrm{~mm}$ lateral from the midsagittal suture, and $9.8 \mathrm{~mm}$ ventral from the surface of the skull. The coordinates for the injection targeting the VTA were $5.3 \mathrm{~mm}$ posterior to Bregma, $0.8 \mathrm{~mm}$ lateral from the midsagittal suture, and $8.5 \mathrm{~mm}$ ventral from the surface of the skull. The coordinates for the microinjection targeting the NTS were $12.7 \mathrm{~mm}$ posterior to Bregma, $1.6 \mathrm{~mm}$ lateral from the midsagittal suture, and $8.5 \mathrm{~mm}$ ventral from the surface of the skull. Stereotaxic coordinates for microinjection into the brain were determined using the Rat Brain Atlas (Paxinos \& Watson 2005). Coordinates were verified and refined by use of a water-soluble blue dye and brain sections were visualized by low-power microscopy. Additional verification of the accuracy of the vector delivery was performed by microinjections of rAAV-GFP into the NTS, MBH, and VTA followed by fluorescence imaging of fixed brain sections. Fluorescent images of rAAV-GFP for MBH and VTA were published previously (Scarpace et al. 2012).

\section{Acute administration of leptin}

A single dose of leptin (40 $\mathrm{ng}$ ) was injected into the third cerebral ventricle as described previously (Scarpace et al. 2007). The coordinates for injection are $1.3 \mathrm{~mm}$ anterior to Bregma, $9.4 \mathrm{~mm}$ ventral from the skull surface, and at an angle of 20 degrees anterior to posterior. Rats were killed $1 \mathrm{~h}$ later to assess leptin-mediated STAT3 signaling.

Published by Bioscientifica Ltd. 


\section{Tissue harvest and preparation}

Rats were killed by thoracotomy under 5\% isoflurane anesthetic. Whole blood was taken by cardiac puncture and serum was collected following centrifugation in serum separator tubes. Subsequently, $40 \mathrm{ml}$ of cold saline were perfused through the circulatory system. The perirenal, retroperitoneal, and epididymal white adipose depots along with interscapular brown adipose tissue (BAT) were excised and their individual weights were recorded.

Additionally, $2 \mathrm{~mm}$ coronal sections containing the regions of the $\mathrm{MBH}$, VTA, and NTS were sliced from fresh brains using a micrometer-controlled tissue slicer (Stoelting Co., Wood Dale, IL, USA) and a section or punch of the respective regions was taken as subsequently described. Brain tissue punches or sections (MBH, VTA, or NTS) were removed under a low-power microscope that provides identification of landmarks found in each $2 \mathrm{~mm}$ tissue slice. Aligning a straight edge razor blade with the optic tract ( $-1.5 \mathrm{~mm}$ posterior Bregma), a $2 \mathrm{~mm}$ caudal coronal section was cut. For the $\mathrm{MBH}$, a $1 \times 1 \mathrm{~mm}$ section was taken just lateral to the third ventricle and the ventral most border of the brain slice. Similarly, aligning a straight edge razor blade with the caudal end of the hypothalamus ( $-5 \mathrm{~mm}$ posterior to Bregma), a coronal section was cut $2 \mathrm{~mm}$ posterior. For the $2 \mathrm{~mm}$ section containing the VTA, a $1 \mathrm{~mm}$ diameter punch was centered ventral to the red nucleus parvicellular (RPC), and medial to the border of the substantia nigra (SN). The $2 \mathrm{~mm}$ section containing the NTS was obtained by slicing the brain $1 \mathrm{~mm}$ anterior to the cerebellum edge and $2 \mathrm{~mm}$ anterior to the initial slice. This section, containing the NTS, was further trimmed by discarding the coronal section $1.5 \mathrm{~mm}$ ventral to the fourth ventricle and by discarding the lateral $1 \mathrm{~mm}$ edge. All punches and sections were taken bilaterally. Brain sections and BAT were briefly sonicated in (40 and $300 \mu \mathrm{l}$ respectively) $10 \mathrm{mM}$ Tris, $\mathrm{pH} 6.8$, and 2\% SDS for western blot analysis. Protein was determined by DC Bradford (Bio-Rad).

\section{Serum leptin}

Serum leptin levels were determined by RIA (Millipore, Billerica, MA, USA).

\section{Western blot analysis}

Protein homogenates (MBH, VTA, NTS, $20 \mu \mathrm{g}$; BAT, $5 \mu \mathrm{g}$ ) were separated on a SDS-PAGE gel and electrotransferred onto nitrocellulose membranes (Scarpace et al. 2001). Immunoreactivity was assessed with antibodies specific to uncoupling protein 1 (UCP1; Abcam, Cambridge, MA,
USA) or phospho-tyrosine 705 of STAT3 and reprobed with antibodies specific to STAT3 regardless of phosphorylation state (Cell Signaling, Danvers, MA, USA). Immunoreactivity to P-STAT3 was compared with that for GAPDH (Abcam) and expressed as a ratio. Immunoreactivity was detected with ECL prime (GE Healthcare, Piscataway, NJ, USA), scanned by the ChemiDoc XRS + system (Bio-Rad), and quantified using the ImageQuant software (Molecular Dynamics, GE Healthcare).

\section{Imaging analysis of NTS}

Each rat received rAAV-GFP injection into NTS separately. Three weeks after virus injections, animals were killed and perfused with $100 \mathrm{ml}$ PBS, followed by $400 \mathrm{ml}$ ice-cold $4 \%$ paraformaldehyde in 0.1 M PBS, pH 7.4. Brains were placed in $30 \%$ sucrose and stored at $4{ }^{\circ} \mathrm{C}$ until sectioning. A block containing the NTS was cut using a straight edge razor blade. The block containing the NTS was frozen on the freezing stage and $50 \mu \mathrm{m}$ sections were cut. Sections were placed on Superfrost Plus glass slides (Fisher Scientific, Pittsburgh, PA, USA), air-dried, and a cover slip was placed with Vectashield mounting medium (Vector, Burlingame, CA, USA). Digital images of native fluorescence of GFP and contrast-optimized unstained sections in bright field were collected using a motorized Nikon microscope (Tokyo, Japan) equipped with a Nikon DS digital camera interfaced with a computer.

\section{Statistical analysis}

Data were analyzed by one-way ANOVA. A post-hoc test (Newman-Keuls) was applied to determine individual differences between means. A $P$ value of $<0.05$ was considered significant.

\section{Results}

\section{Experiment 1: leptin antagonist overexpression in MBH and VTA}

To identify if leptin receptor function in the VTA has a direct role in body weight and food intake regulation, leptin antagonist overexpression (rAAV-leptin Antg) was targeted to the VTA. Before vector delivery, body weight was not different across groups (control, $260 \pm 6 \mathrm{~g}$; rAAVleptin Antg into $\mathrm{MBH}, 251 \pm 9 \mathrm{~g}$; rAAV-leptin Antg into VTA, $257 \pm 8 \mathrm{~g}$ ). Initially, there was a decrease in body weight due to the surgical delivery of the vector, after which delta body weight steadily increased through day

Published by Bioscientifica Ltd. 


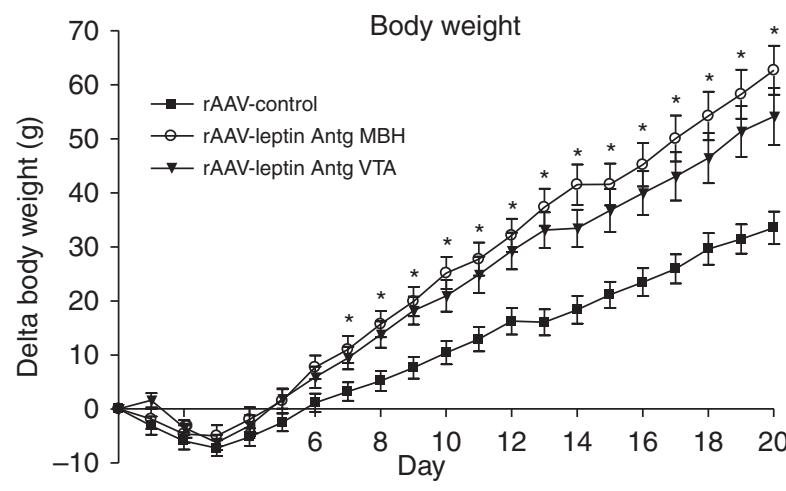

Food consumption

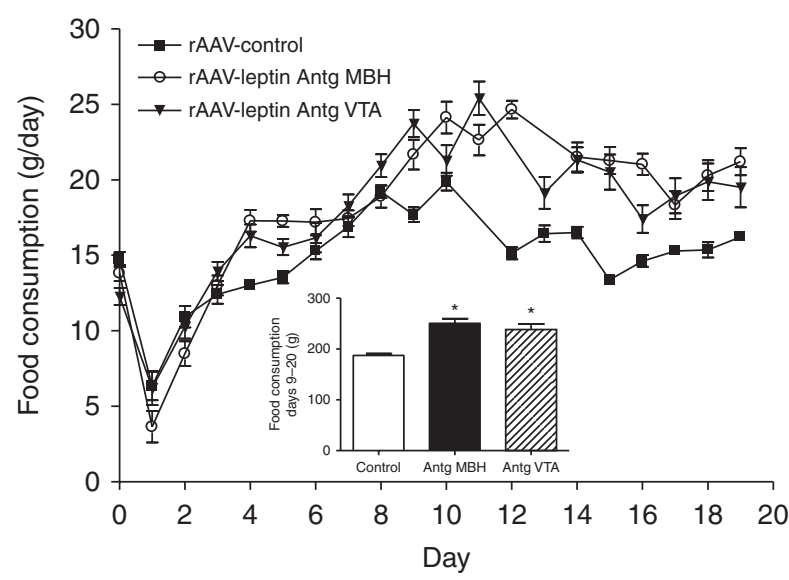

Figure 1

(Top) Change in body weight in rats following administration of control vector (closed squares) or rAAV-leptin antagonist into MBH (rAAV-leptin Antg MBH, open circles) or VTA (closed down triangles). The rAAV-leptin antagonist or control vectors were administered at day 0 in rats maintained on a standard diet. For clarity, rats administered control vector either into the MBH or into the VTA were combined into a single control group (rAAV-control). Delta body weight was significantly different with leptin antagonist treatment $(P<0.005$, one-way ANOVA) beginning at day 7 ( ${ }^{\star} P<0.01, \mathrm{MBH} ;{ }^{*} P<0.05$, VTA by Newman-Keuls post-hoc analysis). Values represent the mean \pm s.E.M. of 13 (control), seven (rAAV-Antg MBH), or eight (rAAV-Antg VTA) rats. (Bottom) Daily food consumption following administration of control vector (closed squares) or rAAV-leptin antagonist into MBH (open circles) or VTA (closed down triangles). (Inset) Cumulative food intake was significantly different with rAAV-leptin antagonist treatment (MBH or VTA) from day 9 to day 19. $* P<0.0001$, one-way ANOVA; $P<0.001$ by Newman-Keuls post-hoc analysis for difference from control.

20 (Fig. 1, top). As expected, overexpression of the leptin antagonist in the $\mathrm{MBH}$ increased body weight gain compared with rats administered the control vector. Interestingly, weight gain showed a trend similar to leptin antagonist treatment in the VTA when compared with treatment in the MBH (Fig. 1, top). Note that one-half of the control rats received the GFP vector into the MBH and the other half received the GFP vector into the VTA. There were no significant differences in delta body weight (GFP $\mathrm{MBH}, 33.8 \pm 3.2 \mathrm{~g}$; GFP VTA, $33.1 \pm 5.6 \mathrm{~g}$ ) between these two control sub-groups. For clarity, rats administered control vector either into the MBH or into the VTA were combined into a single control group (rAAV-control).

Daily food consumption, for the most part, paralleled the change in body weight. There was an initial expected surgery-related decrease in food intake followed by a rapid recovery (Fig. 1, bottom). Beginning at day 9 in $\mathrm{MBH}$ and day 12 in the VTA and continuing through day 19, daily food intake was significantly greater with leptin antagonist compared with rAAV-control, and cumulative food consumption (days 9-19) was $\sim 27-37 \%$ greater (Fig. 1, bottom insert).

\section{Experiment 1: leptin signaling in right and left MBH following leptin antagonist overexpression}

To determine the extent of leptin receptor blockade, leptin signaling following acute injection of $40 \mathrm{ng}$ leptin into the third ventricle was examined in the right and left $\mathrm{MBH}$ at day 20 in rats with leptin antagonist overexpression and corresponding controls. Note that the leptin antagonist was delivered using coordinates that targeted the MBH, right of midline, centered on the ARC. This acute i.c.v. dose of $40 \mathrm{ng}$ leptin corresponded to a dose of leptin that results in half-maximal stimulation based on a previously determined full dose-response curve (Scarpace et al. 2001). As expected, the rAAVcontrol animals, half of whom were injected with ACSF and half with leptin, demonstrated a nearly sixfold increase in P-STAT3 in the right MBH with acute leptin administration when compared with ACSF administration (Fig. 2 top, first two bars). However, in rats with leptin antagonist overexpression in the right $\mathrm{MBH}$, acute leptin stimulation failed to elevate P-STAT3, suggesting that the delivered antagonist fully blocked leptin signaling (Fig. 2, top, third bar). Surprisingly, leptin antagonist overexpression in the VTA attenuated the acute leptin signaling in the right $\mathrm{MBH}$. Although there was a twofold elevation in P-STAT3 observed, it was not significantly different from control (Fig. 2, top, fourth bar).

When the left MBH (contralateral to antagonist vector delivery) was examined, there was a predicted stimulation of P-STAT3 by fourfold in rAAV-control animals following the acute leptin injection into the third ventricle. However, in contrast to the right $\mathrm{MBH}$, no blockade of leptin signaling was observed in the left MBH by either antagonist delivery to the right $\mathrm{MBH}$ or antagonist delivery into VTA, thus confirming the limited spread of

Published by Bioscientifica Ltd 

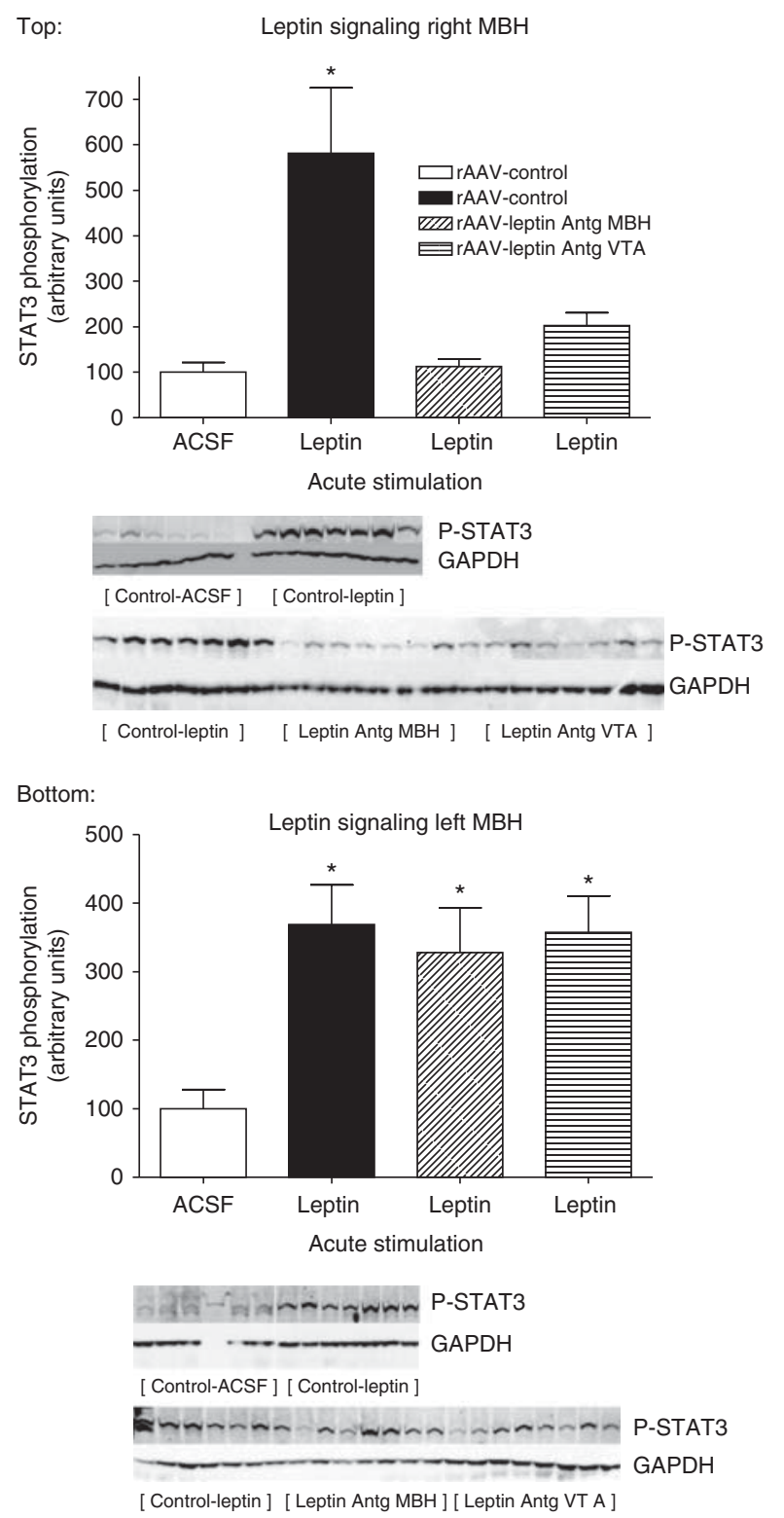

Figure 2

STAT3 phosphorylation following a single i.c.v. injection of ACSF (open bars) or $40 \mathrm{ng}$ leptin in rats administered control vector (solid bars), rAAV-leptin antagonist into the right MBH (hatched bars), or rAAV-leptin antagonist into the VTA (striped bars) 20 days earlier. STAT3 phosphorylation was assessed $1 \mathrm{~h}$ later in the right MBH (Top) or left MBH (Bottom), and expressed as the ratio of STAT3 phosphorylation to GAPDH. Values represent the mean \pm s.E.M. of six to eight rats per group. Western analysis required two gels. Samples from control leptin groups were present on both gels and used for normalization across gels. The value of ACSFinjected control for each individual tissue is arbitrarily set at 100 with S.E.M. adjusted proportionally with remaining groups normalized to the level in ACSF-injected control. (Top) $P<0.001$ for difference with treatment by one-way ANOVA. $* P<0.01$ for difference between AAV-control with leptin injection and all other groups by Newman-Keuls post-hoc analysis. (Bottom) $* P<0.025$ for difference with treatment by one-way ANOVA. $\star P<0.05$ for difference between rAAV-control with ACSF injection and all other groups by Newman-Keuls post-hoc analysis. the overexpressed mutant (Fig. 2, bottom). As levels of total STAT3 decreased with leptin antagonist overexpression, changes in P-STAT3 were normalized to immunoreactivity of GAPDH. Protein levels of GAPDH were unchanged across treatments, and patterns of P-STAT3 signaling remained the same after the normalization (data not shown).

In previous studies, using super-maximal doses of leptin $(1 \mu \mathrm{g})$ injected into the third ventricle, we identified a twofold increase in P-STAT3 levels in the VTA compared with ACSF administration (Scarpace et al. 2012). By contrast, in this study, with the sub-maximal dose of $40 \mathrm{ng}$, we were unable to detect any elevation in P-STAT3 signaling following i.c.v. leptin administration (data not shown).

\section{Experiment 1: adiposity and BAT UCP1 levels}

Adiposity levels were determined by the sum of the weights of perirenal, retroperitoneal, and epididymal white adipose tissues at death in Experiment 1. Adiposity levels were increased by 83 and $40 \%$ with antagonist treatment in MBH and VTA respectively (Table 1). Serum leptin levels, another marker of adiposity, paralleled the changes in adiposity with increases of 83 and $54 \%$ respectively (Table 1 ).

Central overexpression of leptin is known to augment UCP1 in BAT (Scarpace et al. 2012). Consistent with this finding, overexpression of the leptin antagonist in the MBH decreased BAT UCP1 protein levels by $53 \%$. However, overexpression of the leptin antagonist in the VTA did not change UCP1 relative to rAAVcontrol (Table 1).

\section{Experiment 2: overexpression of leptin in VTA in conjunction with antagonist overexpression in $\mathrm{MBH}$}

The unexpected finding that leptin receptor blockade of VTA both increases body weight and antagonizes leptin signaling in the $\mathrm{MBH}$ suggests the possibility that disturbances in $\mathrm{MBH}$ leptin receptors are responsible for antagonist-VTA-injected elevation in body weight. To help resolve this issue, we examined the simultaneous overexpression of leptin in the VTA along with the overexpression of leptin antagonist in the MBH. To this end, rAAV-GFP was delivered into VTA and MBH (rAAVcontrol), rAAV-leptin to the VTA and rAAV-GFP to the MBH (rAAV-leptin VTA), and rAAV-leptin to the VTA and rAAV-leptin antagonist to the MBH (rAAV-leptin VTA/Antg MBH).

Published by Bioscientifica Ltd 
Table 1 Adiposity, serum leptin, and BAT UCP1 levels following leptin antagonist overexpression in Experiment 1. Data represent the mean \pm s.E.M. of 13 (control) or seven to eight (experimental groups) rats. Adiposity represents the sum of perirenal, retroperitoneal, and epididymal white adipose tissues at death. The value of UCP1, expressed as UCP1/ $\mathrm{gg}$ BAT protein, in rAAV-control is arbitrarily set at 100 with S.E.M. adjusted proportionally with remaining groups normalized to the level in rAAV-control

\begin{tabular}{|c|c|c|c|}
\hline & rAAV-control & $\begin{array}{l}\text { rAAV-antagonist } \\
\text { into } \mathrm{MBH}\end{array}$ & $\begin{array}{l}\text { rAAV-antagonist } \\
\text { into VTA }\end{array}$ \\
\hline $\begin{array}{l}\text { Adiposity (g) } \\
\text { Serum leptin (ng/ml) } \\
\text { UCP1/mg (arbitrary units) }\end{array}$ & $\begin{array}{c}7.31 \pm 0.43^{a} \\
5.8 \pm 0.3^{a} \\
100 \pm 10.8^{a}\end{array}$ & $\begin{array}{c}12.23 \pm 0.81^{b} \\
10.6 \pm 0.9^{b} \\
46.8 \pm 12.8^{c}\end{array}$ & $\begin{array}{c}10.19 \pm 0.89^{c} \\
8.9 \pm 1.0^{c} \\
87.4 \pm 17.6\end{array}$ \\
\hline
\end{tabular}

${ }^{a} P<0.0002$ (adiposity and serum leptin) or $P<0.05$ (UCP1) for difference among groups at day 14 by one-way ANOVA.

${ }^{\mathrm{b}} P<0.001$ for difference from control group by Newman-Keuls post-hoc analysis.

${ }^{c} P<0.05$ for difference from control group by Newman-Keuls post-hoc analysis.

Leptin gene delivery to the VTA decreased body weight gain and food intake (Fig. 3, top), in a manner similar to our previous report and to the same degree as leptin overexpression in the MBH (Scarpace et al. 2012). Simultaneous overexpression of the leptin antagonist in the MBH and leptin in the VTA resulted in body weight gain and decreased food intake that were less than rAAVcontrol but greater than with leptin in the VTA (Fig. 3, top). Daily food consumption paralleled the body weight changes, with a decrease in food intake with rAAV-leptin vector delivery to the VTA compared with control that was partially attenuated by the simultaneous treatment with the leptin antagonist in the MBH (Fig. 3, bottom).

STAT3 phosphorylation was examined in the right and left MBH and the VTA at death on day 14. As opposed to Experiment 1, where leptin signaling was assessed following acute administration of leptin, in this experiment, no exogenous drug was administered, thus the levels of P-STAT3 reflected those stimulated by vectormediated leptin overexpression in VTA relative to the basal non-stimulated P-STAT3 in control vector-treated animals or those with simultaneous antagonist delivery to the MBH. With respect to the VTA region, leptin overexpression in the VTA stimulated P-STAT3 by less than twofold over basal levels in control rats, and this stimulation was unaffected by simultaneous overexpression of antagonist in the right MBH (Fig. 4). Examination of P-STAT3 in the right and left MBH revealed that leptin overexpression in the VTA resulted in elevated P-STAT3 levels in the right and left MBH (Fig. 5, top and bottom). Further analysis revealed that the simultaneous overexpression of antagonist in the right MBH fully blocked receptor activation in the right $\mathrm{MBH}$, but only partially blocked activation in the contralateral side (Fig. 5, top and bottom).

\section{Experiment 2: adiposity and BAT UCP1 levels}

Adiposity levels were determined by serum leptin levels and the sum of the weights of perirenal, retroperitoneal, and epididymal white adipose tissues at death. Both serum leptin and sum of white adipose tissues were markedly reduced with leptin treatment in the VTA (Table 2). Simultaneous antagonist treatment in the MBH tempered the reductions in adiposity and serum leptin, but not significantly (Table 2). UCP1 levels in BAT were elevated by twofold by leptin overexpression in VTA and this UCP1 stimulation was unaffected by the antagonist treatment in the MBH (Table 2).

\section{Experiment 3: leptin overexpression in NTS with simultaneous antagonist overexpression in $\mathrm{MBH}$}

The NTS is another brain region that has leptin receptors (Grill \& Hayes 2012) and that purportedly participates in leptin-mediated food and body weight regulation (Hayes et al. 2010, Scott et al. 2011). To examine whether the leptin receptors in the $\mathrm{MBH}$ have a role in the leptin response in the NTS, leptin overexpression in the NTS was compared with rAAV-control in the NTS. In addition, to distinguish whether the observed leptin interaction between VTA and MBH is specific, leptin was overexpressed in the NTS with the simultaneous overexpression of antagonist in the MBH. Unexpectedly, leptin gene delivery to the NTS failed to alter food consumption or body weight over 14 days compared with control vector treatment (Fig. 6, top). In the group with simultaneous overexpression of the antagonist and leptin in the $\mathrm{MBH}$, there was a predicted increase in both body weight and food consumption due to the presence of the antagonist in the MBH (Fig. 6, top).

Published by Bioscientifica Ltd 


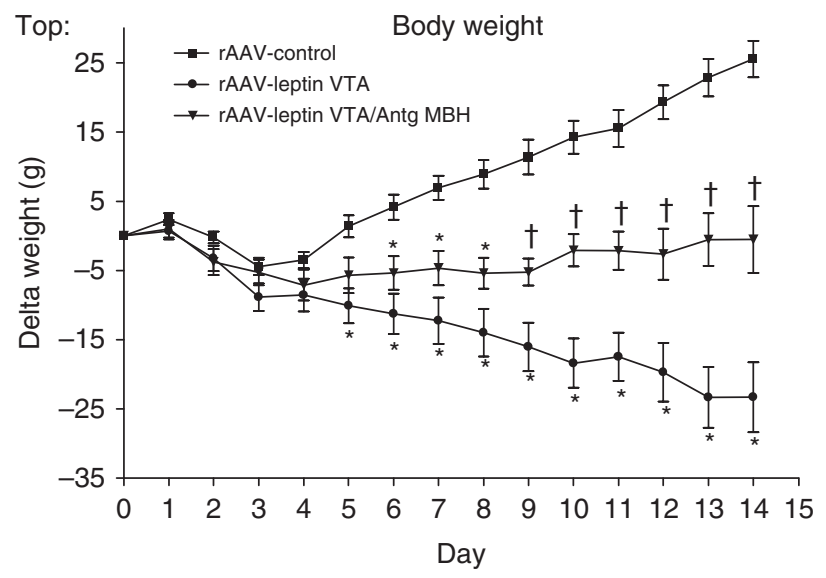

Bottom: Daily food consumption

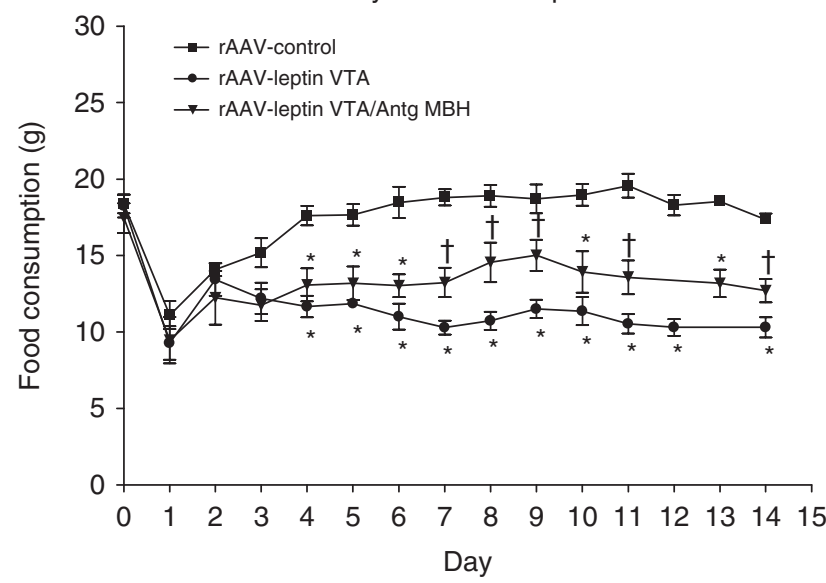

Figure 3

Change in body weight (Top) and daily food consumption (Bottom) following administration of control vector into MBH and VTA (closed squares), rAAV-leptin into VTA with rAAV-control into MBH (open circles) or rAAV-leptin into VTA simultaneously with rAAV-leptin antagonist into MBH (rAAV-leptin VTA/Antg MBH, closed down triangles). The rAAVvectors were administered at day 0 . Values represent the mean \pm s.E.M. of seven to eight rats per group. (Top) Delta body weight significantly diverged from controls starting at day 5 in the rAAV-leptin VTA-treated group $(* P<0.01)$ and at day 6 in rAAV-leptin VTA/Antg MBH-treated group $\left({ }^{*} P<0.01\right)$. The latter group was significantly different from both the controls and rAAV-leptin group starting at day $9\left({ }^{\dagger} P<0.02\right)$ by one-way ANOVA and Newman-Keuls post-hoc analysis. (Bottom) Food consumption significantly diverged from controls starting at day 4 in the rAAV-leptin VTA-treated group $\left({ }^{*} P<0.001\right)$ and $\mathrm{rAAV}$-leptin VTA/Antg MBH-treated group $(* P<0.01)$. The latter group was significantly different from both the controls and the rAAV-leptin group starting at day $7\left({ }^{\dagger} P<0.05\right)$ by one-way ANOVA and Newman-Keuls post-hoc analysis.

STAT3 phosphorylation was examined in the NTS and MBH at death on day 14. Similar to Experiment 2, no exogenous leptin was administered, thus the levels of P-STAT3 reflected those stimulated by vector-mediated leptin overexpression in NTS relative to the basal non-stimulated P-STAT3 in control vector-treated animals. P-STAT3 levels were elevated in the NTS with leptin overexpression and this level of stimulation was unaffected by simultaneous antagonist treatment in the MBH (Fig. 6, bottom). More importantly, there were no changes in P-STAT3 levels in the MBH under any of the conditions investigated (data not shown).

\section{Experiment 4: leptin and leptin antagonist overexpression in NTS}

The unexpected lack of a response to leptin overexpression in the NTS coupled with previous observations that knockdown or ablation of leptin receptors in the NTS increases body weight gain (Hayes et al. 2010, Scott et al. 2011) prompted us to reexamine leptin overexpression in the NTS. However, in this experiment, leptin overexpression was followed for 3 weeks and was compared with leptin antagonist overexpression in the NTS (along with control). Before vector delivery, body weight was not different across groups (control, 326 $\pm 9 \mathrm{~g}$; rAAV-leptin, $321 \pm 3$ g; rAAV-leptin Antg, $312 \pm 5$ g). There was the

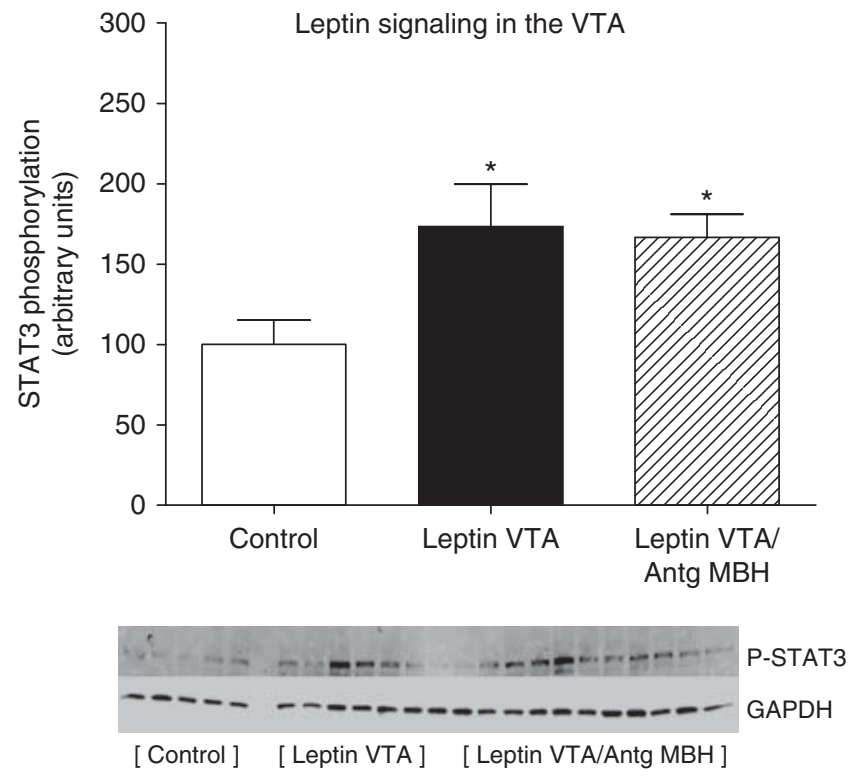

Figure 4

STAT3 phosphorylation in the VTA following treatment for 14 days with rAAV-control vector (open bars), rAAV-leptin into the VTA (solid bars), or rAAV-leptin VTA/Antg MBH (hatched bars). STAT3 phosphorylation represents the stimulation by leptin gene delivery. No further exogenous leptin was administered. Data are expressed as the ratio of STAT3 phosphorylation to GAPDH. Values represent the mean \pm s.E.M. of six to eight rats per group. The value of rAAV-control for each individual tissue is arbitrarily set at 100 with S.E.M. adjusted proportionally with remaining groups normalized to the level in rAAV-control. $P<0.05$ for difference with vector treatment by one-way ANOVA; ${ }^{*} P<0.05$ for difference from rAAV-control by Newman-Keuls post-hoc analysis.

Published by Bioscientifica Ltd. 

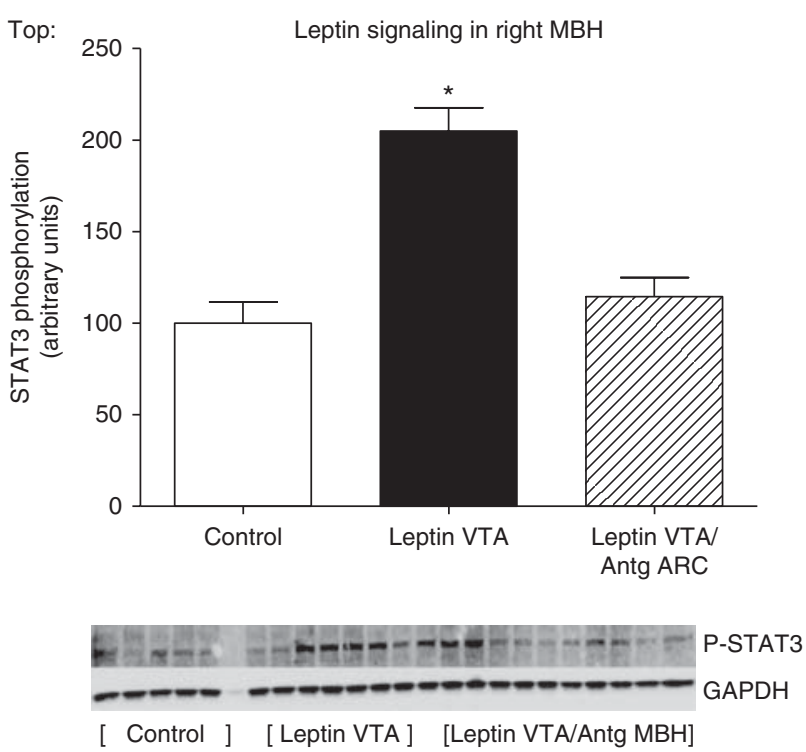

Bottom: $\quad$ Leptin signaling in left $\mathrm{MBH}$

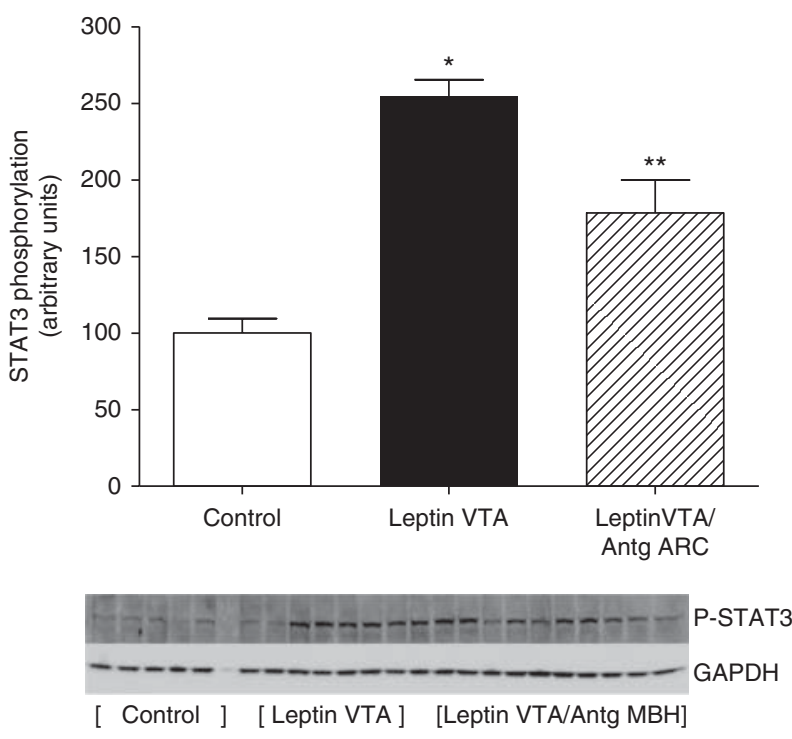

Figure 5

STAT3 phosphorylation in the right MBH (Top) or left MBH (Bottom) following treatment for 14 days with rAAV-control vector (open bars), rAAV-leptin into the VTA (solid bars), or rAAV-leptin VTA/Antg MBH (hatched bars). STAT3 phosphorylation represents the stimulation by leptin gene delivery. No further exogenous leptin was administered. Data are expressed as the ratio of STAT3 phosphorylation to GAPDH. Values represent the mean \pm s.E.M. of six to eight rats per group. The value of rAAVcontrol for each individual tissue is arbitrarily set at 100 with s.E.M. adjusted proportionally with remaining groups normalized to the level in rAAVcontrol. $P<0.0001$ for difference with vector treatment in right $\mathrm{MBH}$ (top) and left MBH (bottom) by one-way ANOVA; ${ }^{*} P<0.001$ for difference between rAAV-leptin and rAAV-control by Newman-Keuls post-hoc analysis; $* * P<0.01$ or for difference between leptin VTA/Antg MBH and either control or rAAV-leptin into VTA by Newman-Keuls post-hoc analysis. usual initial decrease in body weight in all groups followed by a significant increase in delta body weight in the leptin antagonist compared with the control group (Fig. 7, top). Similar to observations in Experiment 3, leptin overexpression in the NTS failed to significantly alter food consumption or body weight over 20 days compared with control vector treatment, although there was a trend toward decrease in body weight (Fig. 7, top). These data reinforced the lack of food intake response for leptin in the NTS. By contrast, antagonist overexpression significantly increased body weight. Interestingly, this increase in body weight was less than half the elevated delta body weight observed with antagonist overexpression in the $\mathrm{MBH}$ (Fig. 1, top).

STAT3 phosphorylation was examined in the NTS and $\mathrm{MBH}$ at death on day 20. Similar to Experiment 3, no exogenous leptin was administered, thus the levels of P-STAT3 reflected those stimulated by vector-mediated leptin overexpression in NTS relative to the basal nonstimulated P-STAT3 in control vector-treated animals. P-STAT3 levels were elevated by nearly 2.5-fold in the NTS with leptin overexpression, whereas antagonist overexpression was not different from control (Fig. 6, bottom). There were no changes in P-STAT3 levels in the $\mathrm{MBH}$ under any of the conditions investigated (data not shown).

\section{Experiment 4: adiposity and BAT UCP1 levels}

The sum of the weights of perirenal, retroperitoneal, and epididymal white adipose tissues was not significantly different at death; however, there was a trend toward decrease with leptin overexpression and increase with antagonist overexpression (Table 3). These trends were paralleled by a significant decrease in serum leptin and a significant increase in serum leptin with leptin and leptin antagonist overexpression respectively (Table 3). UCP1 levels were also significantly increased with leptin gene delivery into the NTS (Table 3 ).

\section{GFP vector image analysis in NTS}

To validate NTS injection parameters, the specificity and potential spread following delivery of the control vector encoding GFP was determined by examining native fluorescence of GFP in selected coronal sections in conjunction with DAPI as a fluorescent nuclear counterstain (not shown) and unstained bright-field images (Fig. 8). Expression was robust in NTS, with abundant numbers of GFP somata in medial, intermediate, and

Published by Bioscientifica Ltd 
Table 2 Adiposity, serum leptin, and BAT UCP1 levels following simultaneous VTA leptin overexpression and MBH leptin antagonist overexpression in Experiment 2. Data represent the mean \pm s.E.M. of seven to eight rats per group. Adiposity represents the sum of perirenal, retroperitoneal, and epididymal white adipose tissues at death. The value of UCP1, expressed as UCP1/ $\mu \mathrm{g}$ BAT protein, in rAAV-control is arbitrarily set at 100 with S.E.M. adjusted proportionally with remaining groups normalized to the level in rAAV-control

\begin{tabular}{lc}
\hline & rAAV-control \\
Adiposity (g) & $7.01 \pm 0.45^{\mathrm{a}}$ \\
Serum leptin (ng/ml) & $4.1 \pm 0.3^{\mathrm{a}}$ \\
UCP1/ $\mu \mathrm{g}$ (arbitrary units) & $100 \pm 13.7^{\mathrm{a}}$ \\
\hline
\end{tabular}

\begin{tabular}{c} 
rAAV-leptin into VTA \\
$1.40 \pm 0.54^{\mathrm{b}}$ \\
$1.4 \pm 0.2^{\mathrm{b}}$ \\
$207.4 \pm 16.7^{\mathrm{c}}$ \\
\hline
\end{tabular}

rAAV-leptin into VTA rAAV
antagonist into MBH
$3.52 \pm 0.76^{c}$
$2.0 \pm 0.4^{\mathrm{b}}$
$201.8 \pm 27.0^{\mathrm{c}}$

a $P<0.0001$ (adiposity and serum leptin) or $P<0.002$ (UCP1) for difference among groups by one-way ANOVA.

${ }^{\mathrm{b}} P<0.001$ for difference from control group by Newman-Keuls post-hoc analysis.

${ }^{c} P<0.01$ for difference from control group by Newman-Keuls post-hoc analysis.

ventrolateral subdivisions. GFP cells were exclusively neuronal based on size and morphology and were observed only in the ipsilateral dorsal medulla. Axons could occasionally be followed from NTS to the contralateral side. Some neurons in overlying structures (vestibular and cuneate nuclei) were observed, but few neurons were transduced ventral to the target.

\section{Discussion}

This study employed recombinant adeno-associated viral techniques to target gene overexpression as a surrogate for pharmacological activation and blockade of leptin receptors specifically in localized brain regions. The expressed gene constructs include secretory sequences. As such, leptin or the dominant negative leptin mutant was expressed within cells comprising the MBH, VTA, or NTS, and the peptide products secreted into the surrounding tissue. Thus, the secreted peptides were available to interact with leptin receptors on nearby cells in a manner similar to endogenous leptin reaching the brain via the circulatory system, but in the present case the activation was limited to the targeted brain region. As detailed below, we demonstrated, using GFP imaging analysis in rats receiving rAAV-GFP vector in either the VTA or MBH (Scarpace et al. 2012) or NTS (current study), that the GFP expression was found mainly in the targeted tissue and adjacent areas, but not in non-injected brain regions.

This study revealed several salient findings regarding the role of leptin action in the VTA and MBH. First, it established the usefulness of targeted overexpression of a leptin mutant as a tool for probing leptin action in specific brain regions. Overexpression of this mutant of rat leptin yields a protein that acts as a neutral leptin receptor antagonist as described previously (Zhang et al. 2007,
Matheny et al. 2009). Brain-wide overexpression increased food consumption, body weight, and adiposity and blocked leptin signaling within the hypothalamus (Matheny et al. 2009). In this study, targeted overexpression of the antagonist to the $\mathrm{MBH}$, right of midline, fully blocked leptin signaling in response to exogenous leptin stimulation. Moreover, the viral vector-mediated overexpression was functionally focused in the delivered region, as evidence by differential blockade in the right and left MBH. Secondly, targeted leptin receptor blockade in the VTA increased body weight gain and food consumption to the same degree as the $\mathrm{MBH}$, suggesting that leptin receptor function in both brain regions equally participates in body weight homeostasis. Thirdly, the simultaneous overexpression of leptin in the VTA in conjunction with leptin antagonist overexpression in the MBH resulted in food intake and body weight gains that were less than with rAAV-control (GFP) but greater than with leptin in the VTA (Fig. 3). This, coupled with the observation that leptin overexpression in the VTA activates leptin receptors in the $\mathrm{MBH}$, suggests that the physiological action of leptin in the VTA has, at least, one component related to P-STAT3 activation in the MBH.

Previous evidence linked leptin receptor activity in the VTA to modulation of HF and sucrose consumption with no discernible effect on body weight (Hommel et al. 2006, Davis et al. 2011). Direct leptin injection into the VTA induced short-term decreases in food consumption and body weight (Bruijnzeel et al. 2011). We reported that chronic leptin overexpression in the VTA ameliorates body weight gain and tempers high-fat food consumption to the same extent as leptin overexpression in the $\mathrm{MBH}$ (Scarpace et al. 2012). Collectively, these data support a role for leptin VTA action in body weight homeostasis. However, in the latter study, the physiological responses

Published by Bioscientifica Ltd 


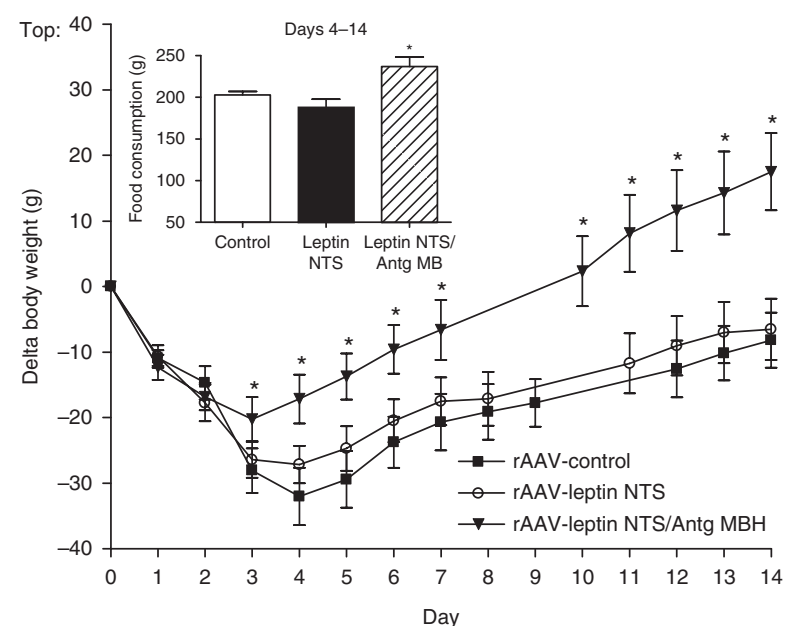

Bottom:
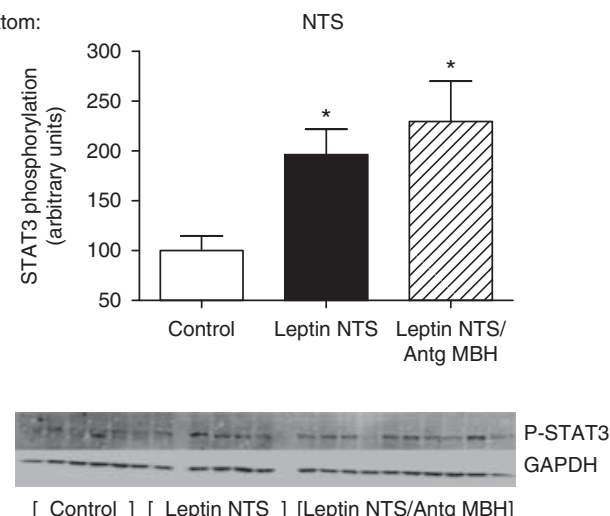

[ Control ] [ Leptin NTS ] [Leptin NTS/Antg MBH]

\section{Figure 6}

(Top) Change in body weight and cumulative food consumption (inset) following administration of control vector into MBH and NTS (closed squares), rAAV-leptin into NTS with rAAV-control into MBH (open circles), or rAAV-leptin into NTS simultaneously with rAAV-leptin antagonist into MBH (rAAV-leptin NTS/Antg MBH, closed down triangles). The rAAVvectors were administered at day 0 . Delta body weight significantly diverged from controls starting at day 4 in rAAV-leptin NTS/Antg MBHtreated group $(P<0.01)$ by one-way ANOVA and Newman-Keuls post-hoc analysis. ${ }^{*} P<0.005$ for difference with vector treatment by one-way ANOVA; $P<0.01$ for difference between rAAV-leptin NTS/Antg $\mathrm{MBH}$ and rAAV-control or $P<0.05$ for difference from leptin NTS by Newman-Keuls post-hoc analysis. Values represent the mean \pm s.E.M. of six to seven rats per group. (Bottom) STAT3 phosphorylation in the NTS at death in the groups described in Fig. 6 top. STAT3 phosphorylation represents the stimulation by leptin gene delivery. No further exogenous leptin was administered. Data are expressed as the ratio of STAT3 phosphorylation to GAPDH. The value of rAAV-control for each individual tissue is arbitrarily set at 100 with s.E.M. adjusted proportionally with remaining groups normalized to the level in rAAV-control. Values represent the mean \pm s.E.M. of six to seven rats per group. $P<0.05$ for difference with vector treatment by one-way ANOVA; ${ }^{*}<0.05$ for difference from rAAV-control by Newman-Keuls post-hoc analysis.

to targeted leptin overexpression in the VTA were associated with elevated P-STAT3 in the MBH, whereas leptin overexpression in the $\mathrm{MBH}$ did not evoke activation of P-STAT3 in the VTA (Scarpace et al. 2012). This study expanded on these findings by simultaneously overexpressing a leptin antagonist in the right $\mathrm{MBH}$ along with the overexpression of leptin in the VTA. The present data revealed that the VTA-leptin-mediated stimulation of P-STAT3 in the right $\mathrm{MBH}$ was completely blocked, suggesting that this elevated P-STAT3 was the result of leptin receptor activation. Thus, the action of leptin in the
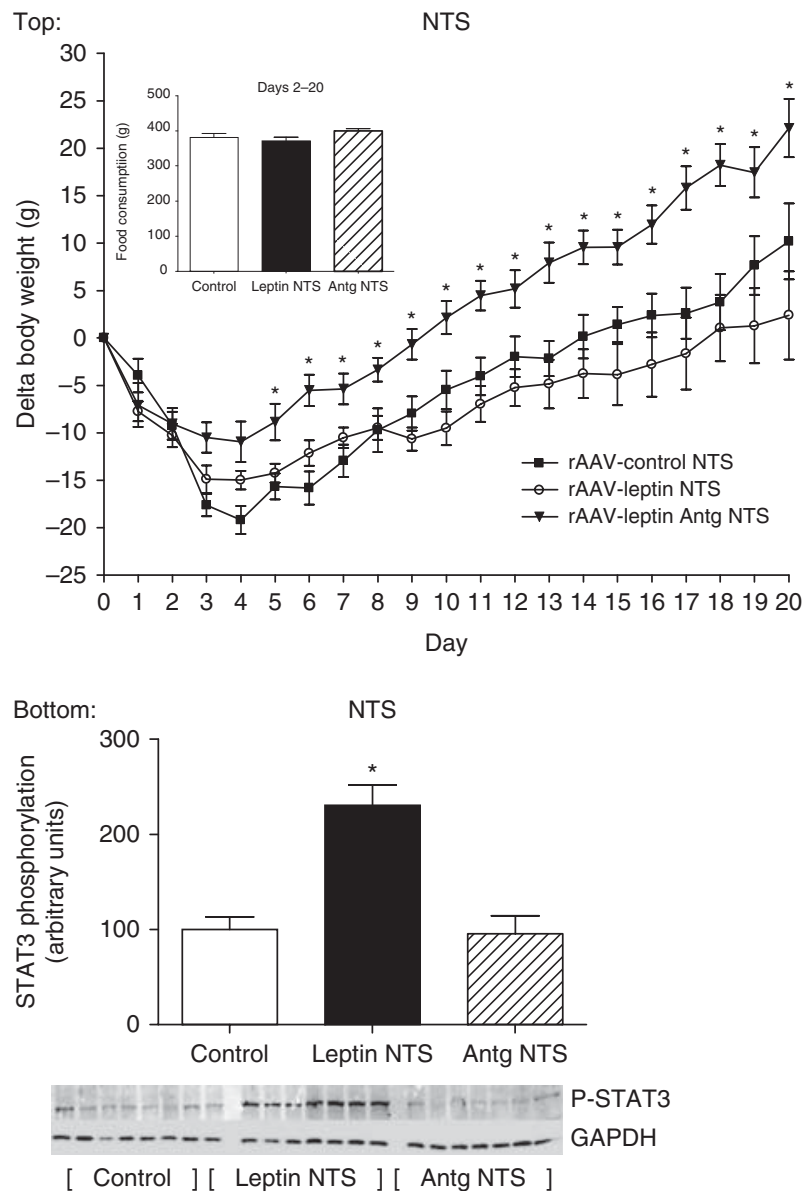

\section{Figure 7}

(Top) Change in body weight and cumulative food consumption (inset) following administration of control vector into NTS (closed squares), rAAV-leptin into NTS (open circles), or rAAV-leptin antagonist into NTS (rAAV-leptin Antg, closed down triangles). The rAAV-vectors were administered at day 0 . Delta body weight in rAAV-leptin Antg significantly diverged from controls starting at day $5(P<0.02)$ by one-way ANOVA and Newman-Keuls post-hoc analysis. Values represent the mean \pm s.E.M. of seven to eight rats per group. (Bottom) STAT3 phosphorylation in the NTS at death in the groups described in Fig. 7 top. STAT3 phosphorylation represents the stimulation by leptin gene delivery. No further exogenous leptin was administered. Data are expressed as the ratio of STAT3 phosphorylation to GAPDH. The value of rAAV-control for each individual tissue is arbitrarily set at 100 with s.E.M. adjusted proportionally with remaining groups normalized to the level in rAAV-control. Values represent the mean \pm S.E.M. of seven to eight rats per group. $P<0.001$ for difference with vector treatment by one-way ANOVA; $* P<0.001$ for difference from rAAV-control or rAAV-leptin Antg by Newman-Keuls post-hoc analysis.

Published by Bioscientifica Ltd. 
Table 3 Adiposity, serum leptin, and BAT UCP1 levels following leptin or leptin antagonist overexpression in NTS from Experiment 4. Data represent the mean \pm S.E.M. of seven rats per group. Adiposity represents the sum of perirenal, retroperitoneal, and epididymal white adipose tissues at death. The value of UCP1, expressed as UCP1/ $\mu$ g BAT protein, in rAAV-control is arbitrarily set at 100 with s.E.M. adjusted proportionally with remaining groups normalized to the level in rAAV-control

\begin{tabular}{|c|}
\hline 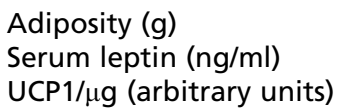 \\
\hline
\end{tabular}

\begin{tabular}{c}
\hline rAAV-control \\
$5.43 \pm 0.34$ \\
$2.80 \pm 0.23^{\mathrm{a}}$ \\
$100 \pm 8.2^{\mathrm{a}}$
\end{tabular}

\begin{tabular}{c} 
rAAV-leptin into NTS \\
\hline $4.45 \pm 0.67$ \\
$1.72 \pm 0.41^{\mathrm{b}}$ \\
$134.2 \pm 7.3^{\mathrm{b}}$ \\
\hline
\end{tabular}

\begin{tabular}{|c|}
\hline rAAV-antagonist into NTS \\
\hline $6.07 \pm 0.31$ \\
$3.46 \pm 0.32^{\mathrm{c}}$ \\
$113.9 \pm 7.5$
\end{tabular}

a $P<0.005$ (serum leptin) or $P<0.05$ (UCP1) for difference among groups at day 20 by one-way ANOVA.

${ }^{\mathrm{b}} P<0.05$ for difference from control group by Newman-Keuls post-hoc analysis.

${ }^{c} P<0.01$ for difference from rAAV-leptin into NTS by Newman-Keuls post-hoc analysis.

VTA may be fully or partially mediated by leptin receptors in the $\mathrm{MBH}$. However, as co-expression of the antagonist in the $\mathrm{MBH}$ only partially blocks the physiological responses to VTA leptin, suggesting a VTA response independent of the $\mathrm{MBH}$. This interpretation is complicated by the observation that antagonist overexpression in the right $\mathrm{MBH}$ does not fully block the VTA-leptinmediated activation of P-STAT3 in the left MBH. Thus, the action of the unblocked component of leptin receptors in the left MBH may account for some of the physiological responses to VTA-leptin overexpression.

The mechanism by which leptin gene delivery to the VTA activates the $\mathrm{MBH}$ could be either specific or inadvertent. The latter includes migration of either the vector or the leptin transgene product. We previously employed GFP as a surrogate marker for viral transduction
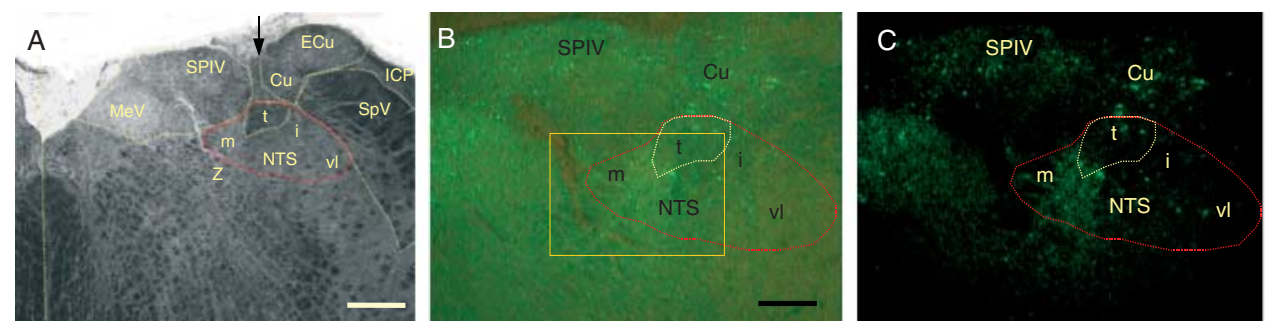

Figure 8

(A) A trans-illuminated (bright-field) image of a coronal $50 \mu \mathrm{m}$ section through the unstained brainstem shows the position of nucleus tractus solitarius (NTS; $t$, tract; $m$, medial; i, intermediate; vl, ventrolateral compartments) in relation to prominent medulla structures as denoted in a standard atlas (Paxinos \& Watson 2005). Arrow denotes vector injection needle track and vertical dotted line denotes midline. Scale bar $500 \mu \mathrm{m}$. $\mathrm{MeV}$, medial vestibular nucleus; SPIV, superior vestibular nucleus; $\mathrm{Cu}$, cuneate nucleus; ECu, external cuneate nucleus; SpV, spinal nucleus of cranial nerve V; ICP, inferior cerebellar peduncle. (B) Combining transillumination to visualize tissue organization (as in $A$ ) with epi-illumination to excite fluorescence of GFP, vector expression was observed to be largely constrained to neurons in and near the NTS. Transduced neurons can be observed clearly in the entire medial-lateral and dorsal-ventral extents of NTS. Some neurons were transduced in vestibular and cuneate nuclei, but

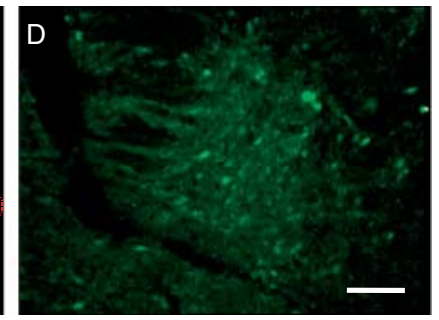

and transgene expression and performed GFP imaging analysis in rats receiving rAAV-GFP vector in either the VTA or MBH. GFP expression was found in the VTA and adjacent SN area after the VTA delivery, while GFP was detected mainly in the lateral and medial arcuate hypothalamic nuclei as well as in the $\mathrm{VMH}$ after $\mathrm{MBH}$ delivery. Therefore, fluorescence of GFP was focused within the injected site and spread into a few indicated neighboring structures but with no appearance in the noninjected MBH or VTA brain region (Scarpace et al. 2012). Moreover, increased leptin expression and elevated leptin protein levels were detected only within the rAAV-leptininjected brain region and were notably absent in the noninjected brain region (Scarpace et al. 2012). It is possible that a small amount of leptin, below our level of detection, diffuses through tissue and is transported through either

few were observed in areas ventral to NTS. Scale bar $250 \mu \mathrm{m}$. (C) Image represents the same field described in $B$ with epi-illumination alone. The field shows the abundance and restricted distribution of transduced neurons, and the absence of fluorescence of GFP outside the immediate vector delivery site. $B$ and $C$ represent the same magnification. (D) At a higher magnification, the approximate area denoted by the box in B shows dozens of transduced NTS neurons expressing GFP closely packed in the medial zone. Epifluorescence is relatively stronger than that in $\mathrm{B}$ and $\mathrm{C}$ due to the $10 \times$ objective focusing the excitation beam onto a smaller region than the $4 \times$ objective used for $B$ and $C$. Trans-illumination intensity was reduced to optimize the image information from both illumination sources, hence the brightness and contrast are different from $B$. Scale bar $100 \mu \mathrm{m}$.

Published by Bioscientifica Ltd. 
the brain's ventricular system or the subarachnoid space (Ruiter et al. 2010). Although this is plausible, it is not apparent. Rats demonstrate decreasing body weight and food intake in a dose-response manner to either i.c.v. infusion of leptin (Wilsey \& Scarpace 2004) or rAAV-leptin delivery (data not shown). Considering that targeted overexpression of leptin to either the MBH or the VTA results in similar decreases in body weight gain and food consumption (Scarpace et al. 2012), it seems unlikely that levels of leptin below detection acting on MBH leptin receptors could result in the same physiological responses as direct leptin overexpression in the $\mathrm{MBH}$. It seems more likely that a neural connection, such as the one along the medial forebrain bundle from the VTA to the hypothalamus (Simmons et al. 1998), underlies the mechanism.

If VTA-leptin stimulation mediates a specific communication between the VTA and $\mathrm{MBH}$, then leptin overexpression in other brain regions should not activate $\mathrm{MBH}$ leptin receptors. It has recently been reported that microinjection of leptin into the hindbrain triggers STAT3 phosphorylation both in the hindbrain and in the hypothalamic neurons (Ruiter et al. 2010). The authors have suggested that hindbrain leptin activates neurons in the hypothalamus via neuronal projections or that leptin reaches leptin-sensitive hypothalamic neurons via the CSF in the subarachnoid space. In the present report, targeted overexpression of leptin in the NTS elevated P-STAT3 levels in the NTS suggesting activation of leptin receptors; however, MBH leptin receptors were not activated. Thus, there appears to be no leptin receptor neurons ascending to the MBH, which modulate STAT3 phosphorylation. This implies that the observed leptin-mediated neural communication between the VTA and MBH is specific, or at least, not universal among all regions expressing leptin receptors.

Interestingly, the targeted overexpression of leptin to the NTS elevated P-STAT3, but there was no significant effect on body weight or food consumption in two separate experiments. Previous reports have established that knockdown of NTS leptin receptors (Hayes et al. 2010) or ablation of leptin receptors in the glucagon-like 1 peptide-expressing neurons in the NTS (Scott et al. 2011) results in hyperphagia and elevated weight gain. The present findings partially support the earlier data, in that overexpression of the leptin antagonist exacerbates body weight gain, although food intake was not different. By contrast, our demonstration that direct leptin activation of the NTS has little role in body weight homeostasis, at first glance, appears to be incongruent with observations following leptin receptor knockdown, ablation, or blockade. However, from a pharmacological perspective, these apparent disparate findings suggest that the leptin receptors in the NTS are saturated by endogenous leptin in the basal state and thus unresponsive to further stimulation by leptin overexpression, but still sensitive to receptor blockade or reductions. This interpretation seems unlikely for two reasons. First, antagonist overexpression did not decrease P-STAT3, and secondly, overexpression of leptin in the NTS increases P-STAT3 by approximately twofold, which is similar to the increase in P-STAT3 levels in MBH when leptin is overexpressed in the MBH (Scarpace et al. 2012), and leptin receptors in the $\mathrm{MBH}$ are fully responsive to exogenous leptin. Alternatively, the NTS leptin receptor could be permissive, supporting the actions of other peptides or facilitating leptin action in other brain sites. It is established that NTS leptin receptors are necessary for the actions of cholecystokinin and that the NTS is a site of integration for leptin and gastrointestinal signals of satiation (Hayes et al. 2010).

Despite the lack of a significant effect of NTS leptin overexpression on food intake or body weight, serum leptin was diminished and UCP1 levels were elevated. This suggests that direct activation of NTS leptin receptors stimulates energy expenditure through activation of BAT. Thus, it is possible that prolonged stimulation of NTS leptin receptors would result in significant differences in body weight compared with control. Collectively, these data suggest that NTS leptin receptors are necessary for normal energy homeostasis, but their role is mostly permissive, with direct activation of NTS leptin receptors yielding a small elevation in energy expenditure, but little effect on body weight.

Fluorescence of GFP in rats receiving rAAV-GFP vector into the NTS indicated that expression was centered in NTS, with abundant fluorescence in neurons in all three subdivisions. The limited expression in vestibular and cuneate nuclei would not be predicted to exert direct action on feeding circuitry. Moreover, any leptin secretion from these nuclei would empty into the fourth ventricle, where the natural CSF flow would take it caudally and laterally rather than toward the MBH. This is consistent with observations that NTS leptin expression did not stimulate P-STAT3 in the $\mathrm{MBH}$, and leptin receptor blockade in $\mathrm{MBH}$, did not reduce leptin-mediated P-STAT3 in the NTS.

Leptin is known to both suppress appetite and augment energy expenditure (Li 2011). One reliable marker of the latter effect of leptin is an increase in nonshivering thermogenesis through induction in UCP1

Published by Bioscientifica Ltd. 
protein in BAT (Scarpace et al. 1997). Although energy expenditure was not directly assessed in this study, BAT UCP1 protein levels were examined. We had previously reported that leptin overexpression in the VTA elevated UCP1 levels in BAT (Scarpace et al. 2012). In this study, UCP1 in BAT was augmented with leptin overexpression in the VTA with or without simultaneous overexpression of the antagonist in the MBH. Moreover, by visual inspection, the BAT in both groups was moderately red compared with control, suggestive of activated UCP1. These data suggest that the VTA has an action independent of that of the MBH in the induction and activation of UCP1. Interestingly, leptin antagonist treatment in the $\mathrm{MBH}$, but not antagonist treatment in the VTA, diminishes UCP1 levels in BAT. A reasonable explanation is that the MBH sets the dominant sympathetic tone for BAT UCP1 induction and this induction is sensitive to any reduction in that $\mathrm{MBH}$-mediated tone by antagonist treatment, whereas the VTA has little role in maintaining the dominant tone, but appears to have an independent stimulatory role.

The most perplexing finding in this report is that leptin antagonist treatment in the VTA attenuates STAT3 phosphorylation in the ipsilateral side of the MBH leptintreated rats. By contrast, in these same animals, P-STAT3 levels in the contralateral side are mostly unaffected similar to leptin-MBH-induced BAT UCP1. Presumably, the unknown mechanism by which leptin application in the VTA activates leptin receptors in the MBH would be subject to leptin receptor blockade, suggesting that the VTA plays a permissive role in MBH signaling.

In summary, leptin function in the VTA participates in the chronic regulation of food consumption and body weight in response to stimulation or blockade of VTA leptin receptors. Moreover, the simultaneous overexpression of the leptin in the VTA with antagonist in the MBH resulted in food intake and body weight gains that were less than with control but greater than with leptin in the VTA. These data along with the elevated UCP1 protein suggest that a component of VTA-leptin action is independent of the $\mathrm{MBH}$, although we cannot rule out participation by the MBH. Furthermore, another component of the physiological action of leptin in the VTA appears to be related to leptin receptor-mediated P-STAT3 activation in the $\mathrm{MBH}$, whose mechanism remains uncertain. Finally, leptin receptors in the NTS are necessary for normal energy homeostasis and demonstrate a mild increase in UCP1 protein, but mostly appear to have a permissive role, while direct leptin activation of NTS leptin receptors has little effect on food consumption or body weight.

These data implicate that an integrative response involving brain regions accounts for the observed physiological effects to the central stimulation of leptin with an emphasis on the interplay between the VTA and the MBH and a mostly permissive role for leptin receptors in the NTS. Leptin action in the VTA has one body weight homeostatic component co-dependent on $\mathrm{MBH}$ leptin receptors and another component apparently independent of the $\mathrm{MBH}$.

\section{Declaration of interest}

The authors declare that there is no conflict of interest that could be perceived as prejudicing the impartiality of the research reported.

\section{Funding}

This work was supported by the NIH DK091710 (P J S) and the Medical Research Service of the Department of Veterans Affairs.

\section{References}

Bruijnzeel AW, Corrie LW, Rogers JA \& Yamada H 2011 Effects of insulin and leptin in the ventral tegmental area and arcuate hypothalamic nucleus on food intake and brain reward function in female rats. Behavioral Brain Research 219 254-264. (doi:10.1016/j.bbr.2011.01.020)

Davis JF, Choi DL, Schurdak JD, Fitzgerald MF, Clegg DJ, Lipton JW, Figlewicz DP \& Benoit SC 2011 Leptin regulates energy balance and motivation through action at distinct neural circuits. Biological Psychiatry 69 668-674. (doi:10.1016/j.biopsych.2010.08.028)

Grill HJ \& Hayes MR 2012 Hindbrain neurons as an essential hub in the neuroanatomically distributed control of energy balance. Cell Metabolism 16 296-309. (doi:10.1016/j.cmet.2012.06.015)

Hayes MR, Skibicka KP, Leichner TM, Guarnieri DJ, DiLeone RJ, Bence KK \& Grill HJ 2010 Endogenous leptin signaling in the caudal nucleus tractus solitarius and area postrema is required for energy balance regulation. Cell Metabolism 11 77-83. (doi:10.1016/j.cmet.2009.10.009)

Hommel JD, Trinko R, Sears RM, Georgescu D, Liu ZW, Gao XB, Thurmon JJ, Marinelli M \& DiLeone RJ 2006 Leptin receptor signaling in midbrain dopamine neurons regulates feeding. Neuron 51 801-810. (doi:10.1016/ j.neuron.2006.08.023)

Li MD 2011 Leptin and beyond: an odyssey to the central control of body weight. Yale Journal of Biology and Medicine 84 1-7.

Matheny M, Zhang Y, Shapiro A, Tümer N \& Scarpace PJ 2009 Central overexpression of leptin antagonist reduces wheel running and underscores importance of endogenous leptin receptor activity in energy homeostasis. American Journal of Physiology. Regulatory, Integrative and Comparative Physiology 297 R1254-R1261. (doi:10.1152/ ajpregu.90449.2008)

Matheny M, Shapiro A, Tumer N \& Scarpace PJ 2011 Region-specific diet-induced and leptin-induced cellular leptin resistance includes the ventral tegmental area in rats. Neuropharmacology $60480-487$. (doi:10.1016/j.neuropharm.2010.11.002)

Paxinos G \& Watson C 2005 The Rat Brain in Stereotaxic Coordinates, 5th edition. Burlington, MA: Elsevier Academic Press.

Ruiter M, Duffy P, Simasko S \& Ritter RC 2010 Increased hypothalamic signal transducer and activator of transcription 3 phosphorylation after

Published by Bioscientifica Ltd. 
hindbrain leptin injection. Endocrinology 151 1509-1519. (doi:10.1210/ en.2009-0854)

Scarpace PJ, Matheny M, Pollock BH \& Tümer N 1997 Leptin increases uncoupling protein expression and energy expenditure. American Journal of Physiology 273 E226-E230.

Scarpace PJ, Matheny M \& Tumer N 2001 Hypothalamic leptin resistance is associated with impaired leptin signal transduction in aged obese rats. Neuroscience 104 1111-1117. (doi:10.1016/S0306-4522(01)00142-7)

Scarpace PJ, Matheny M, Zhang Y, Tumer N, Frase CD, Shek EW, Hong B, Prima V \& Zolotukhin S 2002 Central leptin gene delivery evokes persistent leptin signal transduction in young and aged-obese rats but physiological responses become attenuated over time in aged-obese rats. Neuropharmacology 42 548-561. (doi:10.1016/S00283908(02)00003-5)

Scarpace PJ, Matheny M, Zhang Y, Cheng KY \& Tumer N 2007 Leptin antagonist reveals an uncoupling between leptin receptor signal transducer and activator of transcription 3 signaling and metabolic responses with central leptin resistance. Journal of Pharmacology and Experimental Therapeutics 320 706-712. (doi:10.1124/jpet.106.112813)

Scarpace PJ, Matheny M, Tümer N \& Zhang Y 2012 Leptin overexpression in VTA trans-activates the hypothalamus whereas prolonged leptin action in either region cross-desensitizes. Neuropharmacology 65 90-100. (doi:10.1016/j.neuropharm.2012.09.005)

Scott MM, Williams KW, Rossi J, Lee CE \& Elmquist JK 2011 Leptin receptor expression in hindbrain Glp-1 neurons regulates food intake and energy balance in mice. Journal of Clinical Investigation 121 2413-2421. (doi:10.1172/JCI43703)

Simmons JM, Ackermann RF \& Gallistel CR 1998 Medial forebrain bundle lesions fail to structurally and functionally disconnect the ventral tegmental area from many ipsilateral forebrain nuclei: implications for the neural substrate of brain stimulation reward. Journal of Neuroscience 18 8515-8533.

Wilsey JT \& Scarpace PJ 2004 Caloric restriction reverses the deficits in leptin receptor protein and leptin signaling capacity associated with diet-induced obesity: role of leptin in the regulation of hypothalamic ObRb expression. Journal of Endocrinology 181 297-306. (doi:10.1677/ joe.0.1810297)

Zhang J, Matheny MK, Tumer N, Mitchell MK \& Scarpace PJ 2007 Leptin antagonist reveals that the normalization of caloric intake and the thermic effect of food after high-fat feeding are leptin dependent. American Journal of Physiology. Regulatory, Integrative and Comparative Physiology 292 R868-R874. (doi:10.1152/ajpregu.00213.2006)

Received in final form 23 April 2014 Accepted 25 April 2014
C 2014 Society for Endocrinology Printed in Great Britain
Published by Bioscientifica Ltd. 